\title{
Iliac Artery Aneurysum as Differential Diagnosis of Right Iliacfossa Pain
}

\section{Faris Alaswad*}

Specialist General Surgeon, NMC Speciality Hospital, General Surgery, United Arab Emirates

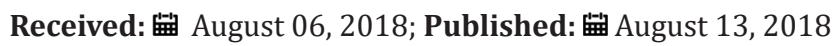

*Corresponding author: Faris Alaswad, Specialist General Surgeon, NMC Speciality Hospital, General Surgery, Alnahda, Dubai, 7832 , United Arab Emirates

Abstract

Our patient presented with symptoms resembling acute appendicitis, during diagnostic laprascopy a retroperitoneal hematoma without palpable Aneurysm was found, because the patient was hemodynamically stable. It was decided to carry out further radiological investigations, a computed tomography revealed a right sided solitary iliac artery aneurysm and a retroperitoneal hematoma and because we were sure about the diagnosis endovascular reconstruction was done, patient recovered nicely, and the retroperitoneal hematoma was reabsorbed spontaneously, and patient was Send home after 7 days.

\section{Case Summary and Discussion}

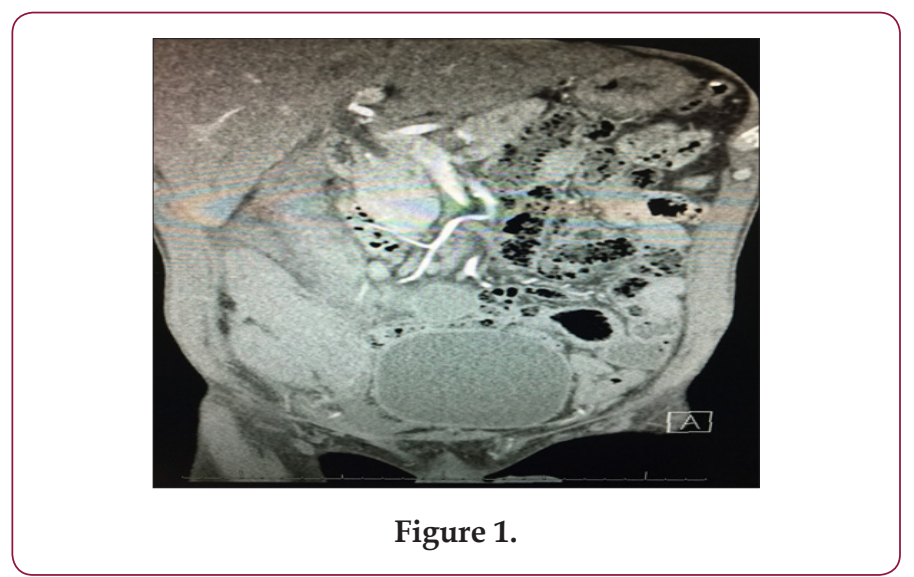

40 years male patient was presented to the emergency department complaining from pain at the right iliac fossa area for the last 48 hours. On clinical examination there was right lower quadrant peritonitis with no palpable mass, body temperature was $37.8 \mathrm{c}$ and the patient leukocytosis was18000, ultrasound was done, and it was not conclusive because of dilated loops of bowel, rebound tenderness was positive, psoas sign was positive. Acute appendicitis was suspected, and laparoscopic appendectomy was planned to be done under general anesthesia. The view was poor and a decision of laparotomy to be done is taken at the same session. There was a normal appendix and a retroperitoneal hematoma on the lateral side of the cecum. The retroperitoneal hematoma was pulsating, and it was a very clear vascular problem, since the patient was hemodynamically stable the operation was terminated with the diagnosis of retroperitoneal hematoma which needs further investigations postoperative CT scan (Figures 1-3) showed a right iliac artery aneurysm with the diameter or $4 \mathrm{~cm}$ and a retroperitoneal hematoma. As with aortic aneurysms size seems to be the most important determinant.
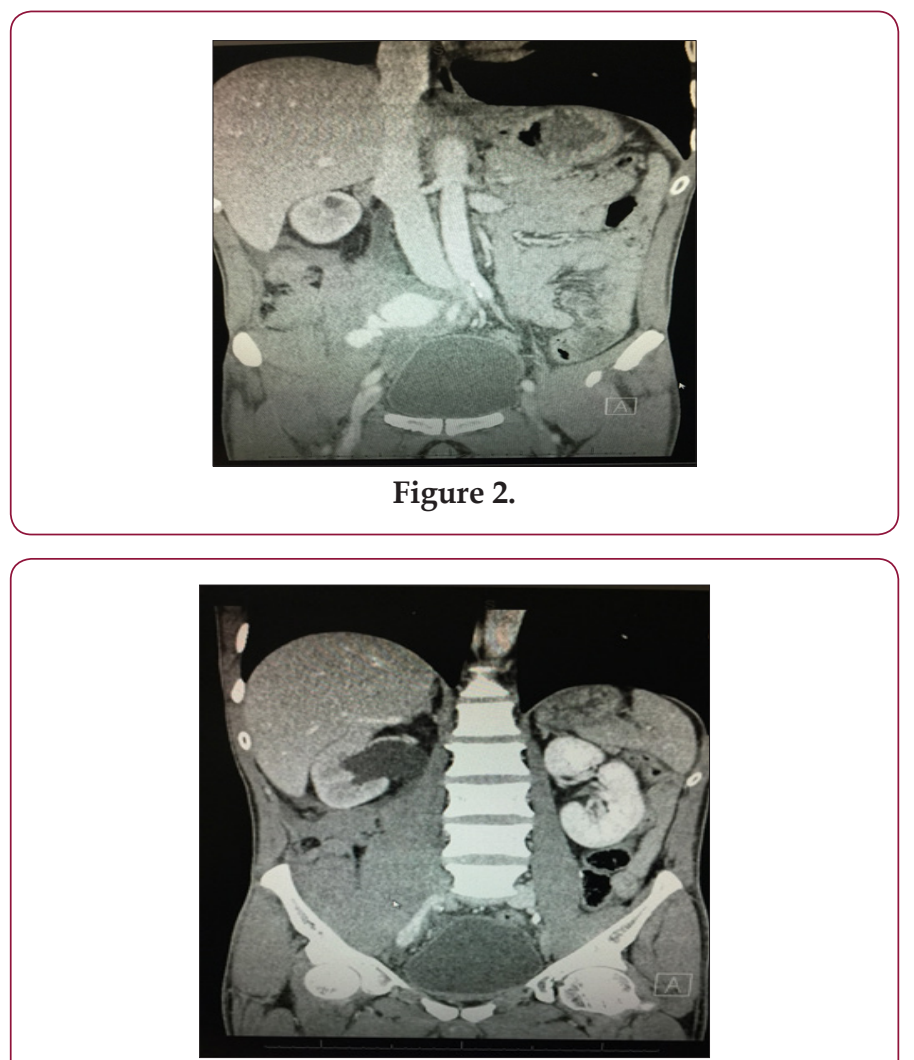

Figure 3. 
For rupture of iliac aneurysms, patients with isolated iliac artery aneurysms Larger than $4 \mathrm{~cm}$ in diameter should undergo elective repair. Involvement of the iliac arteries is seen in $10 \%-$ $20 \%$ of patients with abdominal aortic aneurysms (AAAS) [1]. On the other hand, isolated IAAS are relatively rare, with an estimated prevalence of $0.008 \%-0.03 \%$ based on large autopsy series [2,3]. Like AAAS, IAAS most commonly occur in elderly men. IAAS occur much more frequently in the common and internal iliac arteries than in the external iliac arteries. The most common cause of IAA is atherosclerosis. Other causes include trauma, infection, dissection, excessive athletic effort (e.g. bicycle racing), perianastomotic graft failure, and connective tissue disorders such as marfan syndrome and ehlersdanlos syndrome Like AAAS, IAAS can mimic neurologic, Genito urologic, and gastrointestinal symptoms due to external compression [4,5]. In addition, at clinical examination or conventional angiography, IAAS with luminal Narrowing secondary to aneurysmal thrombosis may mimic arteriosclerosis obliterans $[6,7]$. Hence, it is desirable that iliac artery stenosis or aneurysm be routinely evaluated with CT (sss 4 \& 5) or Magnetic Resonance (MR) imaging prior to angioplasty, even if the entity appears to be a simple stenosis. In some Studies, IAA is defined as enlargement of the artery to a diameter of more than $1.5 \mathrm{~cm}$. As mentioned earlier, the natural course of an IAA consists of progressive expansion with eventual rupture and the risk of rupture increases with aneurysm size [8]. A review of the literature reveals that surgical repair should be recommended for isolated IAAS greater than $3.0-3.5 \mathrm{~cm}$ in diameter, since the smallest reported ruptured IAA was $3 \mathrm{~cm}$ $[2,4,9,10]$. However, this procedure is associated with mortality rates of $7 \%-11 \%$ for elective surgery and $50 \%$ for emergency Surgery IAAS with compressive symptoms (neurologic or urologic symptoms) should be treated with open surgery because endovascular treatment cannot rapidly reduce aneurysm size (Figure 5). In our experience, Aneurysms that are thrombosed with endovascular treatment show a gradual re- duction in size over a long Period of time [7].

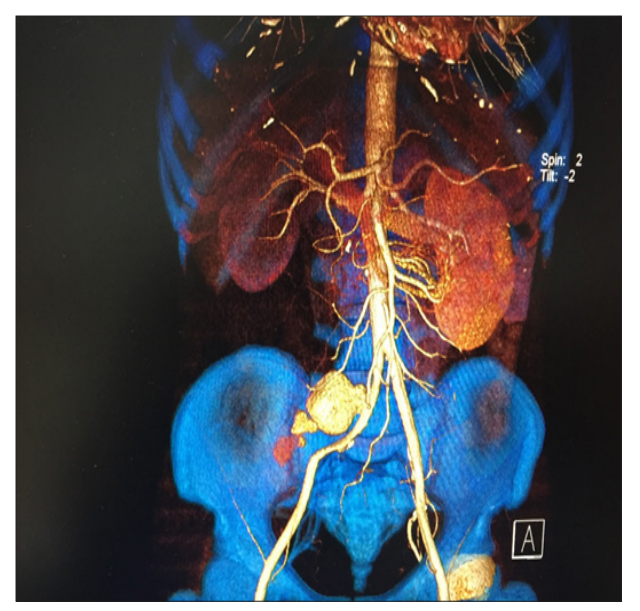

Figure 4 .

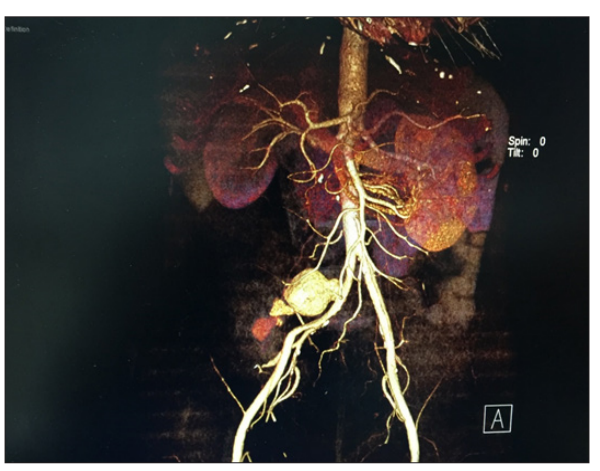

Figure 5 .

\section{Conclusion}

Detailed medical and radiological examination is a must in every surgical case putting in mind the rare causes of right iliac fossa pain as the iliac artery.

\section{References}

1. Krupski WC, Selzman CH, Floridia R, Strecker PK, Nehler MR, et al. (1998) Contemporary management of isolated iliac aneurysms. J Vasc Surg 28(1): 1-11.

2. BrunkwallJ, Hauksson N, Bengtsson H, Bergqvist D, Takolander R, et al. (1989) Solitary aneurysm of the iliac artery system: an estimate of their frequency of occurrence. J Vasc Surg 10: 381-384

3. LuckeB, Rea MH (1921) Studies on aneurysms. JAMA 77: 935-940.

4. Richardson JW, Greenfield LJ (1988) Natural history and management of iliac aneurysms. J Vasc Surg 8(2): 165-171.

5. SacksNP, Huddy SP, Wegner T, Giddings AE (1992) Management of solitary iliac aneurysms. J Cardiovasc Surg (Torino) 33(6): 679-683.

6. Sakamoto I, Sueyoshi E, Hazama S (2005) Endovascular treatment of iliac artery aneurysms. Radiographics 25(1): 213-27.

7. Khosa F, Krinsky G, Macari M (2013) Managing incidental findings on abdominal and pelvic CT and

8. RI, Part 2: white paper of the ACR Incidental Findings Committee II on vascular findings. J Am Coll Radiol 10(10): 789-94.

9. Uberoi R, Tsetis D, Shrivastava V, Robert Morgan, Anna Maria Belli (2011) Standard of practice for the interventional management of isolated iliac artery aneurysms. Cardiovasc Intervent Radiol 34(1): 3-13.

10. Fahrni M, Lachat MM, Wildermuth S, Pfammatter T (2003) Endovascular therapeutic options for isolatedaneurysms with a working classification. Cardiovasc Intervent Radiol 26(5): 443-447.

11. van Sambeek MR, van Urk H (1998) Endovascular treatment of isolated iliac artery aneurysms. Eur J Vasc Endovasc Surg 15: 91-92. 


\section{ISSN: 2574-1241}

DOI: $10.26717 / B J S T R .2018 .07 .001571$

Faris Alaswad. Biomed J Sci \& Tech Res

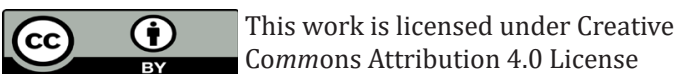

Submission Link: https://biomedres.us/submit-manuscript.php

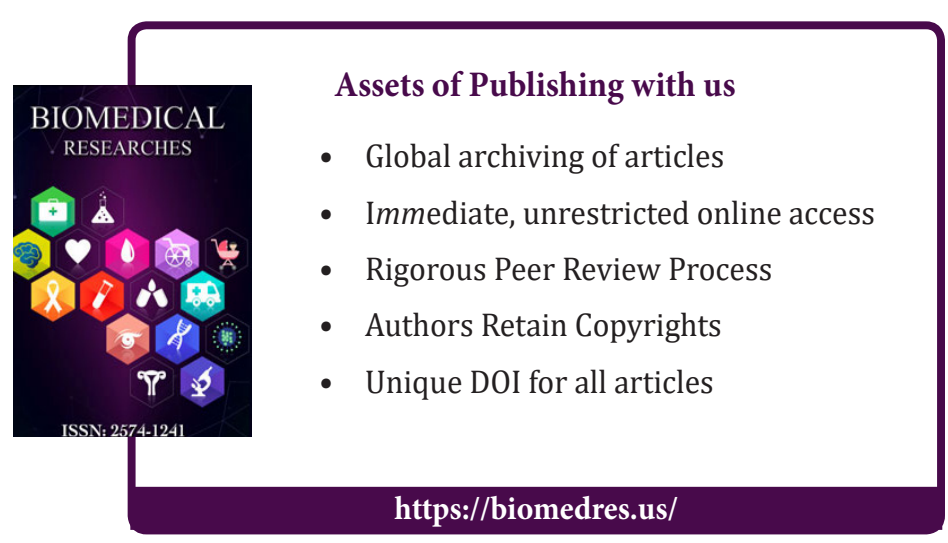

